\title{
Self-Perception of Malocclusion Among Nigerian Adolescents Using The Aesthetic Component of The IOTN
}

\author{
E.A Aikins ${ }^{1, *}, \mathrm{O} . \mathrm{O}$ daCosta $^{2}$, C.O Onyeaso ${ }^{3}$ and M.C Isiekwe ${ }^{2}$ \\ ${ }^{I}$ Department of Child Dental Health, Dental Centre, University of Port Harcourt Teaching Hospital, Port Harcourt, \\ Nigeria \\ ${ }^{2}$ Department of Child Dental Health, Dental School, College of Medicine, University of Lagos, Lagos, Nigeria \\ ${ }^{3}$ Department of Child Dental Health, Faculty of Dentistry, College of Health Sciences, University of Port Harcourt, Port \\ Harcourt, Nigeria
}

\begin{abstract}
Introduction: The practice of orthodontics is very young in South-South Nigeria and there is need for base line data for informed planning. This study was carried out to investigate the self-perception of malocclusion among Nigerian school children aged 12 to 18 years in order to compare their perception with that of an orthodontist and also to determine the influence of gender and age on self-perception.

Materials and Methodology: A total of 612 randomly selected schoolchildren comprising 299 (48.9\%) males and 313 (51.1\%) females with a mean age of $15 \pm 2.0$ years were included in the study, the Aesthetic Component (AC) of the Index of Orthodontic Treatment Need (IOTN) was the instrument used to measure the perception of malocclusion by both the school children and the orthodontist.

Results: Majority of the students $(82.5 \%)$ rated their teeth towards the more attractive end of the scale (Grades 1-4). Although self - perception was not found to be related to gender, older children (16-18 years) had an increased level of perception of need. Males and older children were found to be more in need of treatment by the orthodontist.

Conclusions: A significant difference was found between the orthodontist's rating and the students' ratings of the attractiveness of their occlusions. Age and gender were not found to influence self- perceived orthodontic treatment need. Therefore, for effective orthodontic care, self- perception and not only professional assessment must be taken into consideration when formulating treatment plans to ensure patient satisfaction.
\end{abstract}

Keywords: Children, Malocclusion, Orthodontist's perception, Self-perception.

\section{INTRODUCTION}

Human self-esteem and self-confidence depend to a large degree on an acceptable physical appearance, well proportioned facial features, properly aligned teeth and a pleasing attractive smile [1]. However, the cosmetic impairment of a particular malocclusion is not readily measured because perceptions of malocclusions are highly subjective and perceived by individuals more qualitatively than quantitatively [2]. Most occlusal indices define aesthetics and ultimately orthodontic treatment need from a clinicians point of view only (normative need) without considering patients' social needs. But, perception of dental aesthetics by patients cannot be under estimated because they are the ones receiving treatment and need to gain satisfaction from improved aesthetics $[3,4]$. In most people, the demand for orthodontic treatment is related to their desire to improve their appearance and their degree of attractiveness [3, 5-12].

*Address correspondence to this author at the Department of Child Dental Health Dental Centre University of Port Harcourt Teaching Hospital Port Harcourt, Nigeria; Tel: +2348033131969;

E-mail: elfledaaikins@yahoo.com
The Aesthetic Component (AC) of the Index of Orthodontic Treatment Need (IOTN) (Fig. 1), which is a scale of ten photographs of the occlusion of anterior teeth is a standardized method of assessing dental aesthetics $[2,13]$. Data concerning self-perception of malocclusion based on this index, are available for many populations with figures ranging from $8 \%$ to $38 \%[3,6,14-24]$. However, no such data are available for Nigerian adolescents residing in Rivers State; a place where the practice of orthodontics is relatively new.

Therefore, this study aimed at investigating the selfperception of malocclusion among Nigerian school children aged 12 to 18 years using the Aesthetic Component of IOTN, and to compare their perception with that of an orthodontist as well as to determine the influence of gender and age on self-perception.

\section{MATERIALS AND METHODOLOGY}

A total of 612 students aged 12 to 18 years were randomly selected from six (6) public schools in six (6) different Local Government Areas (Port Harcourt, Ikwerre, Omuma, Tai, Okrika and Asari - Toru) located across Rivers State, Nigeria. Ethical approval was sought and obtained from the Ethics Committee of the University of Port Har- 

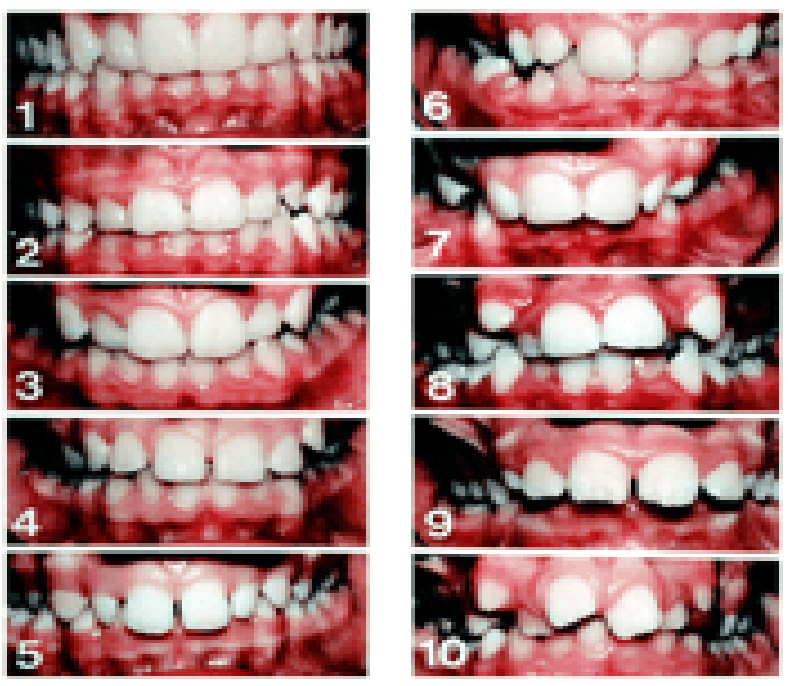

Fig (1). The AC of the IOTN (Brook and Shaw, 1989)

1-4 indicates no need.

5-7 indicates moderate need.

8-10 indicates definite need

court Teaching Hospital. Informed verbal consent was obtained from each of the participants. The data was collected in the school compound during school hours under standardised lighting conditions, with the student seated and the teeth in centric occlusion.

A full intraoral examination was carried out using a wooden spatula and each student's anterior teeth were assessed using the AC of the IOTN with grade 1 as the most attractive and grade 10 as the least attractive (Fig. 1). The grades of the AC which correspond to the numbers on the respective photographs, depicting the levels of treatment need are as follows:

AC Grades 1- 4: No need for orthodontic treatment.

AC Grade 5-7: Borderline / Moderate need for orthodontic treatment.

AC Grade 8-10: Definite need for orthodontic treatment.
The examination was carried out by one author (EAA) who had been previously calibrated in the use of the AC of the IOTN by a senior colleague (COO). None of the students had undergone any form of orthodontic treatment.

The students also assessed their own occlusions using the same scale (AC of the IOTN) and rated their occlusions according to the photograph which most closely matched the attractiveness of their own teeth.

\section{INTRA EXAMINER RELIABILITY}

Intra-examiner reliability was tested using Spearman Rank Correlation Coefficient. Sixty-two students were reexamined a month after their initial examination. A result of 0.94 was obtained, indicating excellent agreement.

\section{STATISTICAL ANALYSES}

The data was analyzed statistically using the SPSS statistical package (Statistical Package for the Social Sciences Version 17.0 for Windows 2009, SPSS, Inc., Chicago, Illinois). Descriptive statistics were used to describe the subjects' perception of their dental aesthetics as compared to the normative assessment. T-test and chi-square statistics were used to analyse the data with statistical significance set at $\mathrm{P}<0.05$. A matrix of Spearman Rank Order Correlation Coefficients was constructed for comparison of self-perceived dental aesthetics of the subjects with normative assessment. Logistic regression analysis was used to determine the influence of sex, age and self assessment of need by participants on professional assessment of need. Preliminary analyses were performed by using univariable models. Next, a multiple logistic regression analysis was then performed to remove the effects of age, sex and self-assessment of need which serve as the confounding factors to produce the adjusted odd's ratios.

\section{RESULTS}

Table 1 shows the gender and age distribution of the sample comprising $299(48.9 \%)$ males and $313(51.1 \%)$ females with a mean age of $15 \pm 2.0$ years. The mean age for the males was $14.9 \pm 1.9$ years, whilst that for females was $15.0 \pm 2.0$.

Table 1. Distribution of the Participants According to Age and Gender

\begin{tabular}{|c|c|c|c|}
\hline \multirow{2}{*}{ Age (years) } & \multicolumn{3}{|c|}{ Frequency (\%) } \\
\cline { 2 - 4 } & Male & Female & Total \\
\hline \hline 12 & $42(14.0)$ & $51(16.3)$ & $93(15.2)$ \\
\hline 13 & $44(14.7)$ & $36(11.5)$ & $90(13.1)$ \\
\hline 14 & $50(16.7)$ & $43(13.7)$ & $75(12.3)$ \\
\hline 15 & $42(14.0)$ & $33(10.5)$ & $99(16.2)$ \\
\hline 16 & $44(14.7)$ & $55(17.6)$ & $108(17.6)$ \\
\hline 17 & $43(14.4)$ & $65(20.8)$ & $64(10.5)$ \\
\hline 18 & $34(11.4)$ & $30(9.6)$ & $612(100)$ \\
\hline Total & $299(48.9)$ & $313(51.1)$ & $15.0 \pm 2.0$ \\
\hline Mean & $14.9 \pm 1.9$ & $15.0 \pm 2.0$ & 15 \\
\hline
\end{tabular}

Student's t test (independent) $=0.82, \mathrm{p}=0.42$ 
Table 2. Gender Distribution of Self-Assessment and Professional (Orthodontist) Assessment of Dental Aesthetics of the Studied Population According to the Aesthetic Component of the Index of Orthodontic Treatment Need

\begin{tabular}{|c|c|c|c|}
\hline \multirow[t]{2}{*}{ Variable } & \multicolumn{3}{|c|}{ Frequency $(\%)$} \\
\hline & Male & Female & Total \\
\hline \multicolumn{4}{|c|}{ Self assessment of need by participants } \\
\hline 5-7 Moderate need & $32(10.7)$ & $35(11.2)$ & $67(10.9)$ \\
\hline $8-10$ Definite need & $23(7.7)$ & $17(5.4)$ & $40(6.5)$ \\
\hline Median & 3 & 3 & 3 \\
\hline \multicolumn{4}{|c|}{ Student's t statistic $=0.06, p=0.95$} \\
\hline \multicolumn{4}{|c|}{ Professional assessment of need } \\
\hline $1-4$ No need & $175(58.5)$ & $222(70.9)$ & $397(64.9)$ \\
\hline Mean & $4.6 \pm 2.8$ & $3.8 \pm 2.5$ & $4.2 \pm 2.7$ \\
\hline Median & 4 & 3 & 4 \\
\hline \multicolumn{4}{|c|}{ Student's t statistic $=3.65, p=0.0003$} \\
\hline
\end{tabular}

Note: Need $>4$, No need $\leq 4$

\section{ORTHODONTIST PERCEPTION OF DENTAL AESTHETICS}

Orthodontist rating revealed that $64.9 \%$ (397 students) had no need for treatment (grades 1-4), 17.5\% (107 students) had a moderate need (grades 5-7) and 17.6\% (108 students) had a definite aesthetic need (grades 8-10) for orthodontic treatment (Table 2).

\section{ORTHODONTIST PERCEPTION COMPARED BY AGE AND GENDER}

There were significant statistical differences between age, gender and the normative orthodontic need as assessed by the AC. Thirteen year-olds had the least orthodontic treatment need of $25 \%$ whilst 17 year-olds had the greatest need for treatment of $43.5 \%$. Male students were statistically $(\mathrm{p}=0.00)$ found to have a greater need for treatment $(41.5 \%)$ than female students $(29.1 \%$ ) (Table 3). A multivariate analysis revealed that as age increased by one unit, participants were 1.1 times more likely to have a professional need for treatment. Males were 1.76 times more likely to have professional need than females (Table 4).

\section{SELF PERCEPTION OF DENTAL AESTHETICS}

However, when the students were asked to rate their own dental attractiveness, $505(82.5 \%)$ scored their teeth as aesthetically acceptable (grades 1-4), 67 (10.9\%) as moderate (grades 5-7) and $40(6.5 \%)$ rated their teeth from grades 8 to 10 (Table 2).

\section{SELF PERCEPTION COMPARED BY AGE AND GENDER}

As depicted in Table 5, majority of the students in each age group rated their teeth towards the more attractive end of the scale. Though there was an increase in the proportion of older children (16 -18 years) rating their teeth in need of orthodontic treatment as compared with the younger schoolchildren, the difference was not statistically significant $(\mathrm{p}$ $>0.05)$. There were almost equal numbers of male $55(18.4 \%)$ and female 52(16.7\%) students rating themselves to be in need of orthodontic treatment. Hence, self perception is not statistically different between genders.

\section{ASSOCIATIONS BETWEEN ORTHODONTIST PER- CEPTION AND SELF-PERCEPTION}

Using Pearson Correlation Coefficient, a weak but significant correlation was found between the orthodontist rating and the students' self-perception $(\mathrm{r}=0.24, \mathrm{P}=0.00)$. One hundred and eight students were rated by the orthodontist to have a definite aesthetic need for orthodontic treatment, out of which 22 also rated themselves likewise. Whilst 107 of the students were rated by the orthodontist as having a moderate need, only 16 were in agreement with this rating. Meanwhile, out of the 397 students assessed not to have a need, 351 of them rated themselves similarly (Table 6). The students who perceived themselves to have a need for treatment were 2.91 times more likely to have a professional need than those without a self-perceived need (Table 4).

\section{DISCUSSION}

The perception that potential patients have of the need for orthodontic treatment cannot be ignored because it is these patients that gain satisfaction from improved aesthetics and even function $[3,4,10]$. Thus, the knowledge of self- perception of malocclusion, assessment of orthodontic treatment need, (self-perceived as well as professional) and their comparisons for any given population are vital issues in modern orthodontic practice. 
Table 3. Relationship Between Age, Gender and Professional (Orthodontist) Assessment of Need According to the Aesthetic Component of the Index of Orthodontic Treatment Need

\begin{tabular}{|c|c|c|c|c|c|c|c|}
\hline \multirow[t]{2}{*}{ Variable } & \multicolumn{2}{|c|}{ Professional Assessment of Need (\%) } & \multirow[t]{2}{*}{$\chi^{2}$} & \multirow[t]{2}{*}{ Odd ratio } & \multicolumn{2}{|c|}{$95 \% \mathrm{CI}$} & \multirow[t]{2}{*}{$\mathbf{p}$} \\
\hline & $\begin{array}{c}\text { Need } \\
(n=215)\end{array}$ & $\begin{array}{c}\text { No Need } \\
(\mathrm{n}=397)\end{array}$ & & & Lower & Upper & \\
\hline \multicolumn{8}{|l|}{ Age (years) } \\
\hline 12 & 25 (26.9) & $68(73.1)$ & 3.27 & 0.64 & 0.38 & 1.07 & 0.07 \\
\hline 13 & $20(25.0)$ & $60(75.0)$ & 4.14 & 0.58 & 0.33 & 1.01 & $0.04 *$ \\
\hline 14 & $34(36.6)$ & $59(63.4)$ & 0.10 & 1.08 & 0.66 & 1.74 & 0.75 \\
\hline 15 & $32(42.7)$ & $43(57.3)$ & 2.13 & 1.44 & 0.86 & 2.42 & 0.14 \\
\hline 16 & $35(35.4)$ & 64 (64.6) & 0.00 & 1.10 & 0.63 & 1.62 & 0.96 \\
\hline 17 & $47(43.5)$ & $61(56.6)$ & 4.05 & 1.54 & 0.99 & 2.40 & $0.04 *$ \\
\hline 18 & $22(34.4)$ & $42(65.6)$ & 0.02 & 0.96 & 0.54 & 1.71 & 0.89 \\
\hline \multicolumn{8}{|l|}{ Gender } \\
\hline Male & $124(41.5)$ & $175(58.5)$ & 10.31 & 1.73 & 1.22 & 2.45 & $0.00^{*}$ \\
\hline Female & $91(29.1)$ & $222(70.9)$ & 10.31 & 0.58 & 0.41 & 0.82 & $0.00 *$ \\
\hline
\end{tabular}

*Significant

Note: The upper limit of the $95 \%$ confidence interval for age 13 years and the lower limit of the interval for age 17 years are approximately equal 1 (i.e. as if the odds ratios did not cross 1 ). That is why the corresponding p-values appeared to be significant.

Table 4. Multivariable Logistic Regression to Examine the Predictors of Professional Assessment of Need

\begin{tabular}{|c|c|c|c|c|c|c|c|c|}
\hline Variable & $\begin{array}{l}\text { Unadjusted } \\
\text { Odds ratio }\end{array}$ & \multicolumn{2}{|c|}{$95 \% \mathrm{CI}$} & p-Value & $\begin{array}{c}\text { Adjusted Odds } \\
\text { Ratio }\end{array}$ & \multicolumn{2}{|c|}{$95 \% \mathrm{CI}$} & p-value \\
\hline Age (year) & $1.10 *$ & 1.02 & 1.21 & 0.02 & $1.10^{*}$ & 1.00 & 1.20 & 0.04 \\
\hline Sex (Male/Female) & $1.73 *$ & 1.24 & 2.42 & 0.001 & $1.76^{*}$ & 1.25 & 2.49 & 0.001 \\
\hline Self need (Yes/No) & $3.02 *$ & 1.97 & 4.36 & $<0.001$ & $2.91 *$ & 1.89 & 4.50 & $<0.001$ \\
\hline
\end{tabular}

*Significant

Note: Unadjusted odds ratio did not remove the effects of confounders, whereas the adjusted odds ratio did.

Table 5. Associations Between Age, Gender and Self-Assessment of Orthodontic Treatment Need According to the Aesthetic Component of the Index of Orthodontic Treatment Need

\begin{tabular}{|c|c|c|c|c|c|c|c|}
\hline \multirow[t]{2}{*}{ Variable } & \multicolumn{2}{|c|}{ Self Assessment of Need (\%) } & \multirow[t]{2}{*}{$\chi^{2}$} & \multirow{2}{*}{$\begin{array}{c}\text { Odd } \\
\text { Ratio }\end{array}$} & \multicolumn{2}{|c|}{$95 \% \mathrm{CI}$} & \multirow[t]{2}{*}{$\mathbf{p}$} \\
\hline & $\begin{array}{c}\text { Need } \\
(n=107)\end{array}$ & $\begin{array}{c}\text { No Need } \\
(n=505)\end{array}$ & & & Lower & Upper & \\
\hline 12 & $12(12.9)$ & $81(87.1)$ & 1.59 & 0.66 & 0.33 & 1.31 & 0.21 \\
\hline 13 & $8(10.0)$ & $72(90.0)$ & 3.57 & 0.49 & 0.21 & 1.09 & 0.06 \\
\hline 15 & $11(14.7)$ & $64(85.3)$ & 0.47 & 0.79 & 0.38 & 1.61 & 0.49 \\
\hline 16 & $17(17.2)$ & $92(82.8)$ & 0.01 & 0.97 & 0.53 & 1.78 & 0.93 \\
\hline 17 & $25(23.1)$ & $83(76.9)$ & 2.92 & 1.55 & 0.55 & 2.64 & 0.09 \\
\hline 18 & $15(23.4)$ & $49(76.6)$ & 1.76 & 1.52 & 0.78 & 2.93 & 0.19 \\
\hline
\end{tabular}


Table 6. Associations Between Self-Assessment and Professional (Orthodontist) Assessment of Orthodontic Treatment Need According to the Aesthetic Component of the Index of Orthodontic Treatment Need

\begin{tabular}{|c|c|c|c|c|}
\hline \multirow[t]{2}{*}{ Self-Perceived Need } & \multicolumn{4}{|c|}{ Professional Need (\%) } \\
\hline & Definite & Moderate & No Need & Total \\
\hline Definite need & $22(55.0)$ & $8(20.0)$ & $10(25.0)$ & 40 \\
\hline Moderate need & $15(22.4)$ & $16(23.9)$ & $36(53.7)$ & 67 \\
\hline No need & $71(14.1)$ & $83(16.4)$ & $351(69.5)$ & 505 \\
\hline Total & 108 & 107 & 397 & 612 \\
\hline
\end{tabular}

$X^{2}=50.95, \mathrm{df}=4, \mathrm{p}=0.00$

In Rivers State, Nigeria, where this study was carried out, the practice and teaching of orthodontics is relatively new. Thus, this cross-sectional study of self- perception of malocclusion in 612 randomly selected $12-18$ year-old Nigerian secondary schoolchildren residing in Rivers State will provide valuable data for the adolescents residing in the State and allow for informed planning of orthodontic services.

Research has proven that most patients seek orthodontic treatment principally for aesthetic improvement [5, 25]. Teenagers, in particular have been found to attach great importance to an attractive dental appearance $[3,7,8,10,16$, 26] and have also been shown to have developed an oral perceptual awareness [27, 28]. Adolescence is the time when concern over appearance and facial attractiveness is developing, which translates to an increased awareness of body image [6]. Thus, the self perception of malocclusion is an important parameter in treatment planning for adolescent populations.

In this study, using the AC, $17.5 \%$ of the students perceived a need for orthodontic treatment. This result is higher than that of a similar study carried out in South- Western Nigeria by Kolawole et al. [22] with treatment need of $8 \%$ in 11 - 14 year-olds and that obtained by Ngom et al. [29] in 12 to 13 year-olds in Senegal $(13.9 \%)$. These differences may be as a result of ethnic variation and the wider age range of the adolescents in this present study. Ethnicity does have an effect on self-perceived need due to differences in acceptable facial appearances and what is deemed as acceptable occlusion by different ethnic groups, it would be useful to validate the IOTN in different ethnic groups. This figure $(17.5 \%)$ is also higher than the subjective need found in the U.K. (6\%) [30], Jordan (9\%) [19], Saudi Arabia (14.5\%) [1], and Peru $(12.8 \%)$ [31]. It is, however, comparable with $18.7 \%$ found in Saudi Arabia among 11-16 year-olds [20] and 5.8\% definite need obtained in Malaysia [24] but much lower than $65 \%$ and $21.8 \%$ subjective need, respectively reported among visually and hearing impaired Saudi Arabian adolescents [20].

In the present study, there were no significant age or gender differences in the participants' self-perceived need for orthodontic treatment, and this is probably due to the subjects' general lack of awareness of the presence of malocclusion. This finding is in agreement with a previous Nigerian study [8],where almost equal numbers of male $(79.8 \%)$ and female $(83.6 \%)$ participants respectively perceived a need for treatment $(\mathrm{p}>0.05)$ as well as other studies in U.K. [23, 30] Saudi Arabia [1] and U.S.A. [28] However, in other studies carried out in South-Western Nigeria [32] and North
Jordan [19], females and older school children tended to rate their dentition towards the more attractive end of the AC scale whereas in a Latvian study [33], female children felt more in need of treatment than male children.

There were significant gender and age differences in the orthodontist's assessment of treatment need, $(p<0.05)$. The increase of orthodontic treatment need with age seen in this study is probably due to the fact that untreated malocclusion worsens with age as the permanent occlusion becomes established [34]. When assessed professionally, male adolescents had a significantly greater need for treatment than females. This is consistent with the findings of Burden et al. [35], but at variance with the findings by Onyeaso [36] where more females were found to be in need of treatment than males. However, it must be noted that the finding by Onyeaso [36] was in a demand population and more females sought orthodontic care in that Nigerian study. It also disagrees with the findings from other studies conducted in Nigeria [8, 10, 32, 37], Tanzania [6], Senegal [29], France [38], Kuwait [18], Latvia [33] and Iran [39] where there were no gender or age differences. Although, our findings corroborate that of Burden et al. [35], no adequate explanation can be made for this gender difference.

In this study, a weak but positive correlation between self - perceived and normative orthodontic treatment need according to the AC of the IOTN was obtained. This is comparable to that obtained in a study carried out on schoolchildren by Kolawole et al. [22] in Western Nigeria ( $\mathrm{r}=0.252$, $\mathrm{p}=0.00)$ and Kerosuo et al. [18] $(\mathrm{r}=0.209, \mathrm{p}=0.05)$ in $\mathrm{Ku}-$ wait but lower than the figure obtained by Otuyemi et al. [32] $(r=0.35)$ in a previous study also carried out much earlier in South-Western Nigeria.

\section{CONCLUSIONS}

A significant difference was found between the orthodontist's rating and the students' ratings of the attractiveness of their occlusions. Age and gender were not found to influence self- perceived orthodontic treatment need. Therefore, for effective orthodontic care, self- perception and not only professional assessment must be taken into consideration when formulating treatment plans to ensure patient satisfaction.

\section{ACKNOWLEDGEMENT}

None declared

\section{CONFLICTS OF INTEREST}

None declared. 


\section{REFERENCES}

[1] Albarakati SF. Self-perception of malocclusion of Saudi patients using the aesthetic component of the IOTN index. Pak Oral Dent J 2007; 27: 45-51.

[2] Evans R, Shaw W. Preliminary evaluation of an illustrated scale for rating dental attractiveness. Eur J Orthod 1987; 9: 314-8.

[3] Grzywacz I. The value of the aesthetic component of the index of orthodontic treatment need in the assessment of subjective orthodontic treatment need. Eur J Orthod 2003; 25: 57-63.

[4] Yeh M, Koochek A, Vlaskalic V, Boyd R, Richmond S. The relationship of 2 professional occlusal indexes with patients' perceptions of aesthetics, function, speech and orthodontic treatment need. Am J Orthod Dentofacial Orthop 2000; 118: 421- 8.

[5] Onyeaso CO, Utomi IL, Ibekwe T. Emotional effects of malocclusion in Nigerian orthodontic patients. J Contemp Dent Pract 2005; 6: $1-10$

[6] Mugonzibwa EA, Kuijpers-Jagtman AM, Van't Hof MA, Kikwilu EN. Perceptions of dental attractiveness and orthodontic treatment need among Tanzanian children. Am J Orthod Dentofacial Orthop 2004; 125: 426- 34

[7] Onyeaso CO, Sanu OO. Psychosocial implications of malocclusion among 12-18 year old secondary school children in Ibadan, Nigeria. Odontostomatol Trop 2005; 109: 39-48.

[8] Onyeaso CO, Arowojolu MO. Perceived, desired and normatively determined orthodontic treatment needs among orthodontically untreated Nigerian adolescents. West Afr J Med 2003; 22: 5-9.

[9] Bernabe E, Flores-Mir C. Orthodontic treatment need in Peruvian young adults evaluated through dental aesthetic index. Angle Orthod 2006; 76: 417-21.

[10] Onyeaso CO, Sanu OO. Perception of personal dental appearance in Nigerian adolescents. Am J Orthod Dentofacial Orthop 2005; 127: $700-6$

[11] Gosney MB. An investigation into some of the factors influencing the desire for orthodontic treatment. Br J Orthod 1986; 13: 87-94.

[12] Al-Hamlan N, Al-Shraim N. Factors that influence perceptions of orthodontic treatment need: literature review. Saudi Dent J 2008; 3:111-20.

[13] Brook PH, Shaw WC. The development of an index of orthodontic treatment priority. Eur J Orthod 1989; 11: 309- 20.

[14] Hamden M, Al-Omari IK, Al-Bitar ZB. Ranking dental aesthetics and thresholds of treatment need: a comparison between patients, parents and dentists. Eur J Orthod 2007; 29: 366-71.

[15] Mugonzibwa EA, Kuijpers-Jagtman AM, van't Hof MA, Kikwilu EN. Comparison between the opinions of Tanzanian parents and their children on dental attractiveness. Angle Orthod 2004; 74: 6370.

[16] Flores-Mir C, Major PW, Salazar FR. Self-perceived orthodontic treatment need evaluated through 3 Scales in a university population. J Orthod 2004; 31: 329-34

[17] Hamdan AM. The relationship between patient, parent and clinician perceived need and normative orthodontic treatment need. Eur J Orthod 2004; 26: 265-71.

[18] Kerosuo H, Al Enezi S, Kerosuo E, Abdulkarim E. Association between normative and self-perceived orthodontic treatment need among Arab high school students. Am J Orthod Dentofacial Orthop 2004; 125: 373-8.

[19] Abu Alhajia ESJ, Al-Nimri KS, Al-Khateeb SN. Self-perception of malocclusion among Jordanian schoolchildren. Eur J Orthod 2005; 27: 292-5.
[20] Al-Sarheed M, Bedi R, Hunt NP. Orthodontic treatment need and self-perception of 11-16 year old Saudi Arabian children with sensory impairment attending special schools. J Orthod 2003; 30: 3944.

[21] Abu Alhajia ESJ, Al-Nimri KS, Al-Khateeb SN. Orthodontic treatment need and demand in 12-14 year old North Jordanian schoolchildren. Eur J Orthod 2004; 26: 261-3.

[22] Kolawole KA, Otuyemi OD, Jeboda SO, Umweni AA. Awareness of malocclusion and desire for orthodontic treatment in 11-14 Year Old Nigerian schoolchildren and their parents. Aust Orthod J 2008; 24: 21-5.

[23] Burden DJ, Pine CM. Self-perception of malocclusion among adolescents. Commun Dent Health 1995; 12: 89-92.

[24] Abdullah MSB, Rock WP. Perception of dental appearance using index of treatment need (aesthetic component) assessments. Commun Dent Health 2002; 19: 161-5.

[25] Shaw WC. Factors influencing the desire for orthodontic treatment. Eur J Orthod 1981; 3: 151-62.

[26] Helm S, Petersen PE, Kreiborg S, Solow B. Effect of separate malocclusion traits on concern for dental appearance. Commun Dent Oral Epidemiol 1986; 14: 217-20.

[27] Baldwin DC. Appearance and aesthetics in oral health. Commun Dent Oral Epidemiol 1980: 8: 244-56.

[28] Tulloch JFC, Shaw WC, Smith A. A comparison of attitudes towards orthodontic treatment in British and American communities. Am J Orthod 1984; 85: 253-9.

[29] Ngom PI, Diagne F, Dieye F, Diop-Ba K, Thiam F. Orthodontic treatment need and demand in Senegalese school children aged 1213 years. Angle Orthod 2007; 2: 323-30.

[30] Mandall NA, McCord JF, Blinkhorn AS, Worthington HV, O'Brien KA. Perceived aesthetic impact of malocclusion and oral self- perception in 14-15 year old Asian and Caucasian children in Greater Manchester. Eur J Orthod 1999; 21: 175-83.

[31] Bernabe E, Flores-Mir C. Normative and self-perceived orthodontic treatment need of a Peruvian university population. Head Face Med 2006; 2: 22

[32] Otuyemi OD, Ugboko VI, Adekoya-Soforowa CA, Ndukwe KC Unmet orthodontic treatment need in rural Nigerian adolescents. Commun Dent Oral Epidemiol 1997; 25: 363-6.

[33] Liepa A, Urtane I, Richmond S, Dunstan F. Orthodontic treatment need in Latvia. Eur J Orthod 2003; 25: 279-84.

[34] Onyeaso CO, BeGole EA. Associations between pretreatment age and treatment time with orthodontic treatment outcome: a comparison by means of two orthodontic indices. Hell Orthod Rev 2008; 1 : $8-20$.

[35] Burden DJ, Mitropoulos CM, Shaw WC. Residual orthodontic treatment need in a sample of 15 and 16 year-olds. Br Dent J 1994 176: $220-4$

[36] Onyeaso CO. Orthodontic treatment need of Nigerian outpatients assessed with the Dental Aesthetic Index. Aust Orthod J 2004; 20: 19-23.

[37] Akpata ES, Jackson D. Overjet values in children and young adults in Lagos. Commun Dent Oral Epidemiol 1979; 7: 174-6.

[38] Souames M, Bassigny F, Zenati N, Riordan PJ, Boy-Lefevre ML. Orthodontic treatment need in French schoolchildren: an epidemiological study using the index of orthodontic treatment need. Eur J Orthod 2006; 28: 605-9.

[39] Borzabadi-Farahani A, Borzabadi-Farahani A, Eslamipour F. The relationship between the ICON index and aesthetic components of the IOTN index. World J Orthod 2010; 11: 43-8.

(C) Aikins et al.; Licensee Bentham Open

This is an open access article licensed under the terms of the Creative Commons Attribution Non-Commercial License (http://creativecommons.org/licenses/by-nc/3.0/) which permits unrestricted, non-commercial use, distribution and reproduction in any medium, provided the work is properly cited. 